\title{
Tuberculin skin test conversion in patients under treatment with anti-tumor necrotizing factor alpha agents
}

\author{
Mohammad-Esmaeil Hejazi ${ }^{1}$, Atefeh Ahmadzadeh ${ }^{1 *}$, Alireza Khabbazi ${ }^{2}$, Aliasghar Ebrahimi ${ }^{1}$, Maryam Farmani ${ }^{1}$ and \\ Yasin Hejazi ${ }^{1}$
}

\begin{abstract}
Background: Despite successful clinical outcomes of biologic medications in patients with chronic rheumatic diseases, some considerable adverse effects such as infections remain a major concern. Possibility of tuberculosis (TB) reactivation over treatment with anti-tumor necrotizing factor (TNF) alpha agents has necessitated a screening test before initiation of treatment. However, screening over the course of treatment is not recommended in those patients with negative baseline screening tests. This study aimed to evaluate the efficacy of tuberculin skin test (TST) before treatment in patients with chronic rheumatologic diseases who were indicated to receive anti-TNFalpha therapy and the necessity of repeating this test over the course of treatment.
\end{abstract}

Methods: In this prospective study, patients with chronic rheumatologic diseases receiving anti-TNF-alpha agents were studied in a two-year period. TST was performed before treatment and those with positive results were excluded from the study. Thereafter, treatment with anti-TNF-alpha agents was initiated with the indicated dose. TST was repeated before administration of biologic treatment until TST became positive or 16 weeks after the initiation of treatment with anti-TNF-alpha.

Results: A total of 51 cases were studied, of whom one patient (1.9\%) was excluded due to positive TST before treatment. All participants received infliximab and the TST test became positive in one patient (2\%) 2 weeks after receiving the first dose. Also, the results of further tests at weeks 6, 10, and 14 were all negative for the remaining patients.

Conclusion: Due to the possibility of TST conversion after administration of anti-TNF-alpha therapy, it is important to consider TB monitoring in patients under treatment with these agents using available methods such as TST.

Keywords: Tuberculin skin test, Anti-TNF-alpha agents, Tuberculosis

\section{Background}

The Community Oriented Program for Control of Rheumatic Diseases (COPCORD) and the International League of Associations for Rheumatology (ILAR) by the collaboration of the World Health Organization (WHO) revealed that rheumatic complains were the commonest

\footnotetext{
* Correspondence: dr.atefeahmadzade@gmail.com

1 Internal medicine department, Tabriz University of Medical Sciences, Tabriz, Iran

Full list of author information is available at the end of the article
}

complaint in the community, and soft tissue rheumatism, ill-defined musculoskeletal symptoms, and osteoarthritis were the most prevalent disorders [1]. The urban COPCORD study in developing countries such as Iran demonstrated that in the population over the age of 15 years rheumatic complains were seen in $41.9 \%$ of people. Degenerative joint disease and inflammatory disorders were also reported in a considerable proportion of patients [2]. Different therapeutic options have been recommended for rheumatologic diseases, such as non-

(C) The Author(s). 2020 Open Access This article is licensed under a Creative Commons Attribution 4.0 International License, which permits use, sharing, adaptation, distribution and reproduction in any medium or format, as long as you give appropriate credit to the original author(s) and the source, provide a link to the Creative Commons licence, and indicate if changes were made. The images or other third party material in this article are included in the article's Creative Commons licence, unless indicated otherwise in a credit line to the material. If material is not included in the article's Creative Commons licence and your intended use is not permitted by statutory regulation or exceeds the permitted use, you will need to obtain permission directly from the copyright holder. To view a copy of this licence, visit http://creativecommons.org/licenses/by/4.0/ The Creative Commons Public Domain Dedication waiver (http://creativecommons.org/publicdomain/zero/1.0/) applies to the data made available in this article, unless otherwise stated in a credit line to the data. 
steroidal anti-inflammatory drugs, traditional diseasemodifying anti-rheumatic drugs (DMARDs), and glucocorticoids [3, 4]. Moreover, numerous biologic therapies have emerged in the recent decades with significantly successful outcomes, including tumor necrosis factoralpha (TNF-alpha) blockers, CTLA4-Ig, anti-interleukin I (IL-1) and anti-IL 6 receptors, and rituximab (an anti CD20 antibody) [5-7]. However, some complications, particularly infections, are not uncommon by using these medications, both as a direct consequence of the treatment or due to the underlying disease process [8-10]. Reactivation of tuberculosis (TB) has also been widely reported in patients receiving biologic therapies, in particular anti-TNF-alpha agents [11-13]. Therefore, tuberculin skin test (TST) or interferon-gamma release assay (IGRA) is strictly recommended before the initiation of therapy [13]. Most current guidelines and expert reviews recommend that in case of the absence of risk factors and clinical suspicion for $\mathrm{TB}$, there is no need for repeating TB screening tests $[13,14]$. However, there are some reports of TB infection in patients under treatment with biologic therapies and negative TST at initiation [15-17]. These reports raise the concern about the inadequacy of a single TST test before initiation of treatment. However, no prospective study has been conducted in this regard. Therefore, we aimed to evaluate the efficacy of TST before treatment in patients with chronic rheumatologic diseases who were indicated to receive anti-TNF-alpha therapy and necessity of repeating this test over the course of treatment.

\section{Methods}

This prospective observational study was conducted on patients (in any age or sex) with a chronic rheumatologic disease referred to Imam Reza Teaching Hospital of Tabriz University of Medical Sciences for receiving antiTNF-alpha agents in a two-year period (March 2017 to March 2019). Patients were excluded if they had a medically confirmed history of active or latent TB infection, household TB contact, or unevaluated symptoms that could possibly be due to TB infection, such as chronic cough. Informed consent was obtained from all participants. TST was performed 10 days before treatment with the standard method by an internal medicine specialist and was confirmed by another internal medicine specialist. Patients with positive TST tests were excluded from the study and referred to the TB control centers for further diagnostic and/or therapeutic procedures. The study was continued with TST negative patients. One week later, TST test was repeated and the positive tests were considered as booster effect; these cases were also excluded from the study. Thereafter, treatment with antiTNF-alpha agents was initiated with the indicated dose. Infliximab was administered at weeks 0,2 , and 6 and then every 8 weeks. The timing of the TST test and infliximab administrations are illustrated in Fig. 1. TST was repeated by the same person with the same procedure before administration of treatment until TST became positive or 16 weeks after the initiation of treatment with anti-TNF-alpha.

TST was done by an internal specialist on the volar side of the left forearm with the Mantoux method. Ten units of tuberculin purified protein derivative (PPD) was injected intradermally and the injected site was marked (PPD RT23; Staten Serum Institute, Copenhagen, Denmark). The appearance of any induration was evaluated $72 \mathrm{~h}$ after injection using the ballpoint method [18]. The same procedure was repeated each time the TST was performed. An induration of more than $5 \mathrm{~mm}$ was considered in patients receiving immunosuppressive drugs, such as methotrexate or cyclosporine; otherwise, $10 \mathrm{~mm}$ or higher was considered positive. Also, any increase in diameter of induration of TST was defined as positive TST $[19,20]$.

\section{Statistical analysis}

Continuous data were reported as mean and standard deviation. The frequency and percentage of qualitative variables were also reported. SPSS version 24 was used for all analyses.

\section{Results}

A total of 51 patients participated in this study, out of whom one patient with ankylosing spondylitis (AS) and a positive TST before initiation of treatment was excluded from the study. The study was conducted on 50 patients, including 28 males (56\%) and 22 females (44\%). The mean age was $31.2 \pm 6.55$ years (range: $20-50$ years). Also, 33 patients (66\%) had AS and 17 patients (34\%) had rheumatoid arthritis (RA). Concurrent use of methylprednisolone was reported in 17 (34\%) patients (Table 1). All patients had received Bacillus Calmette-Guérin (BCG) vaccination in their childhood.

All patients with negative TST included in our study received infliximab with the standard dose. Before administration of the second dose of infliximab (2 weeks after the first dose of infliximab), a male 37-year-old patient with AS developed a positive TST (induration, 8 $\mathrm{mm}$; Table 2). The TST induration of this patient prior to biologic treatment was $3 \mathrm{~mm}$; he received indomethacin concomitantly but did not receive prednisolone or other non-steroidal anti-inflammatory drugs. Moreover, he had no household TB contact. The patient was referred to TB control center for further evaluation and the study continued with the remaining patients. However, no other positive TST cases were seen when TST was repeated in the following weeks. In addition, none of the patients had symptoms of TB. 


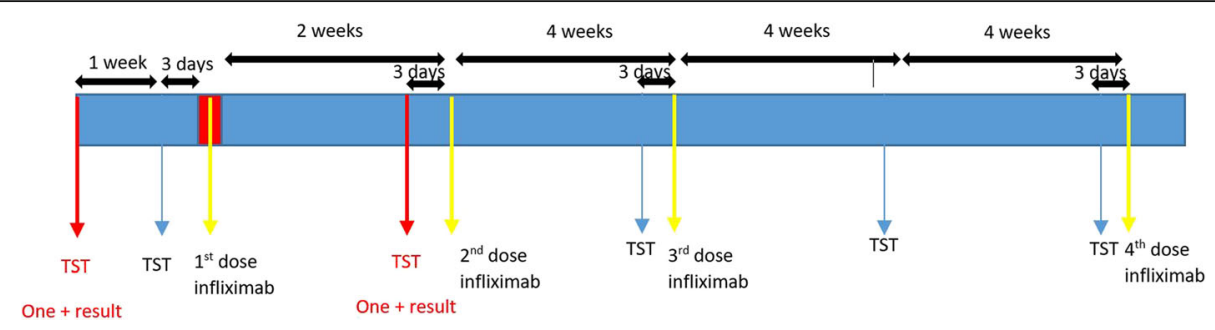

Fig. 1 Timing of the administration of infliximab and tuberculin skin test (TST)

\section{Discussion}

The possibility of $\mathrm{TB}$ reactivation by anti-TNF-alpha treatment has been well-established by several studies, and guidelines recommend performing screening tests before initiation of these drugs. However, the majority of current guidelines suggest that there is no need for re-

Table 1 Characteristics of included patients

\begin{tabular}{|c|c|}
\hline Total number & 50 \\
\hline Age (mean $\pm S D$ years) & $31.2 \pm 6.6$ \\
\hline$\leq 18(n, \%)$ & 0 \\
\hline $18-39(n, \%)$ & $42(84 \%)$ \\
\hline $40-49(n, \%)$ & $7(14 \%)$ \\
\hline$\geq 50(n, \%)$ & $1(2 \%)$ \\
\hline BCG vaccination at birth $(n, \%)$ & $50(100 \%)$ \\
\hline \multicolumn{2}{|l|}{ Type of disease } \\
\hline Ankylosing spondylitis & $33(66 \%)$ \\
\hline Rheumatoid arthritis & 17 (34\%) \\
\hline \multicolumn{2}{|l|}{ Biologic treatment } \\
\hline Infliximab (n, \%) & $50(100 \%)$ \\
\hline Each dose (mg) & 200 \\
\hline \multicolumn{2}{|l|}{ Other treatments } \\
\hline Indomethacin (n, \%) & $13(26 \%)$ \\
\hline Daily dose (mg) & 150 \\
\hline Naproxen (n, \%) & $4(8 \%)$ \\
\hline Daily dose (mg) & 1500 \\
\hline Diclofenac (n, \%) & $16(32 \%)$ \\
\hline Daily dose (mg) & 200 \\
\hline Hydroxychloroquine (n, \%) & 17 (34\%) \\
\hline Daily dose mean \pm SD dose (mg) & $270.5 \pm 98.5$ \\
\hline Methotrexate $(n, \%)$ & $17(34 \%)$ \\
\hline Weekly dose mean \pm SD dose $(\mathrm{mg})$ & $13.8 \pm 3.3$ \\
\hline \multicolumn{2}{|l|}{ Prednisolone } \\
\hline Daily dose mean \pm SD (mg) & $5.29 \pm 1.21$ \\
\hline$\leq 2.5 \mathrm{mg}(\mathrm{n}, \%)$ & $1(2 \%)$ \\
\hline$=5 \mathrm{mg}(\mathrm{n}, \%)$ & $13(26 \%)$ \\
\hline$\geq 7.5 \mathrm{mg}(\mathrm{n}, \%)$ & $3(6 \%)$ \\
\hline No prednisolone (n, \%) & $33(66 \%)$ \\
\hline
\end{tabular}

screening TB infection after initiation of biologic treatments [14]. We evaluated the sufficiency of TST in patients with chronic rheumatic diseases indicated to receive biologic therapy. Our results demonstrated that there is a possibility of positive TB infection after administration of biologic drugs despite a negative prior screening test (conversion of TST) that can be detected by repeating TST over the course of treatment. Although this was seen only in one over 50 patients included in the study, neglecting this finding and poor detection and management of this highly communicable disease can lead to terrible consequences.

Several studies have revealed the risk of TB infection in patients who receive TNF-alpha inhibitors [21-23]. Askling et al. investigated the Swedish Inpatient Register RA cohort (62.321 patients) and reported that 230 individuals in this cohort were diagnosed with $\mathrm{TB}$ during the 14 years follow-up period, of whom, 15 patients had received TNF-alpha inhibitors (11 patients were treated with infliximab) [24]. A conversion from negative TST to positive after treatment with anti-TNF-alpha has also been reported by some studies. Park et al. reported a considerable ratio of $32.6 \%$ of patients having a conversion from negative to positive TST by using biologic medications [17]. Also, Slouma et al. reported that there were two cases of active pulmonary TB among patients receiving anti-TNF-alpha therapy with initially negative TST and QuantiFERON-TB Gold test [16]. Another study by Mobini et al. also reported a case of seropositive RA under treatment with infliximab that got an active TB infection despite a previous negative $\mathrm{TB}$ screening test [15]. This finding has also been reported for patients with non-rheumatic diseases. Celine Debeuckelaere et al. reported two patients with chronic inflammatory bowel disease (IBD) that developed a TB infection after treatment with anti-TNF-alpha agents, despite a negative screening test [25]. Also, a Korean study reported de novo TB infection in $3.1 \%$ of IBD patients after anti-TNF-alpha therapy [26].

A panel of experts recommend that annual TB screening test should be considered in patients with RA, AS, psoriatic arthritis (PsA), or psoriasis under treatment with anti-TNF-alpha agents if they travel or work in 
Table 2 TST results

\begin{tabular}{|c|c|c|c|c|}
\hline \# & Time of test & Number of tested patients & Result & \\
\hline \multirow[t]{2}{*}{$1 \#$} & 10 days before treatment & 51 & Positive * & $1(1.9 \%)$ \\
\hline & & & Negative & $50(98.1 \%)$ \\
\hline \multirow[t]{2}{*}{ 2\# } & 3 days before treatment & 50 & Positive & 0 \\
\hline & & & Negative & $50(100)$ \\
\hline \multirow[t]{2}{*}{ 3\# } & 3 days before the second dose & 50 & Positive * & $1(2 \%)$ \\
\hline & & & Negative & 49 (98\%) \\
\hline \multirow[t]{2}{*}{ 4\# } & 3 days before the third dose & 49 & Positive & 0 \\
\hline & & & Negative & $49(100)$ \\
\hline \multirow[t]{2}{*}{$5 \#$} & Four weeks after the third dose & 49 & Positive & 0 \\
\hline & & & Negative & $49(100)$ \\
\hline \multirow[t]{2}{*}{$6 \#$} & 3 days before fifth dose & 49 & Positive & 0 \\
\hline & & & Negative & $49(100)$ \\
\hline
\end{tabular}

TST positive patients were referred to TB control centers and TB infection was confirmed

situations where TB exposure is likely regardless of negative screening test at baseline [13]. However, this has not been adequately appreciated in the current guidelines.

There are two predominant screening tests for TB including TST and IGRA. Despite well-known falsenegative and false-positive TST results, the standard screening test is still TST along with a comprehensive medical history and chest X-ray [27]. Furthermore, TST is simpler, has lower costs, and is a widely available test. Therefore, in our study we did not perform IGRA and only TST was conducted as a screening test. Meanwhile, we attempted to diminish the disadvantages of TST; for example, TST was administrated meticulously by an expert and under supervision to reduce the negative impact of misperformance. We did not have any falsepositive results as both TST-positive patients (before and after treatment) were confirmed to have active TB by further evaluations. Nonetheless, we could not roll out false-negative TST in our patients due to their immunosuppression treatment. Oral prednisolone is reported to have some impact on TST results; however, this impact is predominantly dose dependent [28]. Kleinert et al. and Ponce de Leon et al. demonstrated that 7.5-10 mg/day may impair TST results [29]. However, majority of our patients received prednisolone with a dose of equal or less than $5 \mathrm{mg} /$ day. Regarding the patient who presented positive TST after treatment, it is unlikely that the negative TST before treatment was due to immunosuppression because he was not under treatment with immunosuppressive drugs and he received the medications with the same dose along with infliximab.

A conversion in TST, defined as a change from negative to a positive test, can occur when a new or enhanced hypersensitivity arise due to de novo TB infection or nonTB mycobacteria, including BCG vaccination [19]. This reaction has been variedly reported to occur 3 to 7 weeks after exposure [19]. In our study, positive TST was seen after 2 weeks of baseline TST ( 2 weeks after initiation of treatment). This could be due to the booster effect; however, considering that we conducted a second TST 3 days before treatment to roll out this phenomenon, a booster effect was also unlikely to be considered for our patient.

TNF-alpha has an important role in both the host immune response to TB infection and in its immunopathology [30]. It is produced by a variety of immune cells in response to various pathogens, such as lipopolysaccharide or viral and bacterial infections [31]. TNF-alpha in response to TB infection brings about several positive effects. The main receptor of TNF-alpha, acting against TB infection is TNF receptor 1 (TNFR1) [32]. In vitro studies have demonstrated that TNFR1 is essential in both granuloma formation and in susceptibility to intracellular pathogens during TB infection. This results in controlling the mycobacteria and preventing their dissemination [30]. Therefore, it is conceivable that inhibition of this mediator by anti-TNF-alpha agents leads to poor immune reaction potency against TB infection.

The global prevalence of RA is more than AS; but in our study $66 \%$ of patients who received infliximab were AS. The main reason was our center's strategy for treatment of RA. We use biologics after failing combination therapy with three DMARDs for controlling the disease activity. However, some rheumatologists use rituximab as the first biologic for treating seropositive RA.

Our study had some limitations. It was better to perform IGRA and chest X-ray for more comprehensive screening of the patients. But due to our center's protocol and some aforementioned reasons we only performed TST. Moreover, due to the relatively small number of patients in our study we found only one positive TST after 
initiation of treatment. It could be possible to detect more positive cases in a larger sample size.

\section{Conclusion}

Our study demonstrated the possibility of TST conversion (positive TST) after the administration of infliximab. Therefore, it is important to consider re-screening TB in patients receiving infliximab after initiation of the treatment even if the screening tests were negative before treatment.

\section{Abbreviations}

TNF: Anti-tumor necrotizing factor; PPD: Purified protein derivative;

TB: Tuberculosis; TST: Tuberculin skin test; TNFR1: TNF receptor 1

\section{Acknowledgements}

We would like to thank the members of the Connective Tissue Diseases Research Center of Tabriz University of Medical Sciences for their sincere collaboration.

\section{Authors' contributions}

Conceived the idea: $\mathrm{MH}$ and AA. Designed the study methodology: AA, AK, $A E$, and $Y H$. Conducted the study: AA, MF, and AK. Analyzed the data: MF and $A E$. Interpreted the results: $A A, M H$, and MF. Composed the early draft: $A A$ and MF. Revised and edited the final manuscript: $M H$ and AE. Approved the manuscript: $M H, A A, A K, A E, M F$, and $Y H$.

\section{Funding}

This study was funded by the Tabriz University of Medical Sciences, Tabriz, Iran.

\section{Availability of data and materials}

All Data and material are available upon request.

\section{Ethics approval and consent to participate}

Ethical clearance was sought from medical ethics committee of Tabriz University of Medical Sciences, Tabriz, Iran. Written informed consent was obtained from the participants.

\section{Consent for publication}

All authors have provided formal consent to publish this work.

\section{Competing interests}

The authors declare that they have no competing interests.

\section{Author details}

'Internal medicine department, Tabriz University of Medical Sciences, Tabriz, Iran. ${ }^{2}$ Connective Tissue Diseases Research Center, Tabriz University of Medical Sciences, Tabriz, Iran.

Received: 9 January 2020 Accepted: 17 June 2020

Published online: 02 July 2020

\section{References}

1. Chopra A. Disease burden of rheumatic diseases in India: COPCORD perspective. Indian J Rheumatol. 2015:10(2):70-7.

2. Davatchi F, Jamshidi AR, Banihashemi AT, Gholami J, Forouzanfar MH, Akhlaghi $\mathrm{M}$, et al. WHO-ILAR COPCORD study (stage 1, urban study) in Iran. J Rheumatol. 2008;35(7):1384.

3. Singh JA, Saag KG, Bridges Jr. SI, Akl EA, Bannuru RR, Sullivan MC, et al. 2015 American College of Rheumatology Guideline for the Treatment of Rheumatoid Arthritis. Arthritis Rheumatol. 2016;68(1):1-26.

4. Sadat-Ebrahimi SR, Parnianfard N, Vahed N, Babaei H, Ghojazadeh M, Tang S, et al. An evidence-based systematic review of the off-label uses of lisinopril. $\mathrm{Br} J$ Clin Pharmacol. 2018:84(11):2502.

5. Barone M, Notarnicola A, Lopalco G, Viggiani MT, Sebastiani F, Covelli M, et al. Safety of long-term biologic therapy in rheumatologic patients with a previously resolved hepatitis B viral infection. Hepatology. 2015;62(1):40-6.
6. Moots RJ, Naisbett-Groet B. The efficacy of biologic agents in patients with rheumatoid arthritis and an inadequate response to tumour necrosis factor inhibitors: a systematic review. Rheumatology. 2012; 51(12):2252-61.

7. Rubbert-Roth A. Assessing the safety of biologic agents in patients with rheumatoid arthritis. Rheumatology. 2012;51(suppl_5):v38-47.

8. Salvana EMT, Salata RA. Infectious complications associated with monoclonal antibodies and related small molecules. Clin Microbiol Rev. 2009:22(2):274-90.

9. Hamilton CD. Infectious complications of treatment with biologic agents. Curr Opin Rheumatol. 2004:16(4):393-8.

10. Ochoa C, Rajaram P, Tanukonda S, Sadikot RT. Infectious Complications In Patients Receiving Biologic Therapy. A44 DRUG INDUCED AND RARE LUNG DISEASE: American Thoracic Society; 2016. p. A1592-A.

11. Cantini F, Nannini C, Niccoli L, Petrone L, Ippolito G, Goletti D. Risk of tuberculosis reactivation in patients with rheumatoid arthritis, ankylosing spondylitis, and psoriatic arthritis receiving non-anti-TNF-targeted biologics. Mediat Inflamm. 2017;2017:8909834.

12. Cantini F, Niccoli L, Capone A, Petrone L, Goletti D. Risk of tuberculosis reactivation associated with traditional disease modifying anti-rheumatic drugs and non-anti-tumor necrosis factor biologics in patients with rheumatic disorders and suggestion for clinical practice. Expert Opin Drug Saf. 2019;18(5):415-25.

13. Cantini F, Nannini C, Niccoli L, lannone F, Delogu G, Garlaschi G, et al. Guidance for the management of patients with latent tuberculosis infection requiring biologic therapy in rheumatology and dermatology clinical practice. Autoimmun Rev. 2015;14(6):503-9.

14. Iannone F, Cantini F, Lapadula G. Diagnosis of latent tuberculosis and prevention of reactivation in rheumatic patients receiving biologic therapy: international recommendations. J Rheumatol Suppl. 2014:91:41-6.

15. Mobini M, Niksolat F, Ghasemian R, Sharifpour A, Valipour S. De novo tuberculosis during anti-tumor necrosis factor-alpha therapy in a rheumatoid arthritis patient with negative initial screening. J Mazandaran Univ Med Sci. 2017:26(144):382-8.

16. Slouma M, Mahmoud I, Saidane O, Bouden S, Abdelmoula L. Latent tuberculosis infection screening prior to biological treatment in Tunisian patients. Therapies. 2017;72(5):573-8.

17. Park JH, Seo GY, Lee JS, Kim T-H, Yoo D-H. Positive conversion of tuberculin skin test and performance of interferon release assay to detect hidden tuberculosis infection during anti-tumor necrosis factor agent trial. J Rheumatol. 2009:36(10):2158.

18. Cohn DL, O'Brien RJ, Geiter LJ, Gordin F, Hershfield E, Horsburgh C. Targeted tuberculin testing and treatment of latent tuberculosis infection. MMWR Morb Mortal Wkly Rep. 2000;49(6):1-54

19. Nayak S, Acharjya B. Mantoux test and its interpretation. Indian Dermatol Online J. 2012;3(1):2-6.

20. Pérez-Lu JE, Cárcamo CP, García PJ, Bussalleu A, Bernabé-Ortiz A. Tuberculin skin test conversion among health sciences students: a retrospective cohort study. Tuberculosis. 2013:93(2):257-62.

21. Murdaca G, Spanò F, Contatore M, Guastalla A, Penza E, Magnani O, et al. Infection risk associated with anti-TNF-a agents: a review. Expert Opin Drug Saf. 2015;14(4):571-82

22. Murdaca G, Colombo BM, Puppo F. Anti-TNF-a inhibitors: a new therapeutic approach for inflammatory immune-mediated diseases: an update upon efficacy and adverse events. London, England: SAGE Publications Sage UK; 2009.

23. Murdaca G, Colombo BM, Cagnati P, Gulli R, Spanò F, Puppo F. Update Upon Efficacy and Safety of TNF-a Inhibitors. Expert Opin Drug Saf. 2012;11(1):1-5.

24. Askling J, Fored CM, Brandt L, Baecklund E, Bertilsson L, Cöster L, et al. Risk and case characteristics of tuberculosis in rheumatoid arthritis associated with tumor necrosis factor antagonists in Sweden. Arthritis Rheumatism 2005;52(7):1986-92.

25. Debeuckelaere C, De Munter P, Van Bleyenbergh P, De Wever W, Van Assche G, Rutgeerts $P$, et al. Tuberculosis infection following anti-TNF therapy in inflammatory bowel disease, despite negative screening. J Crohn's Colitis. 2014;8(6):550-7.

26. Byun JM, Lee CK, Rhee SY, Kim H-J, Kim J-W, Shim J-J, et al. The risk of tuberculosis in Korean patients with inflammatory bowel disease receiving tumor necrosis factor-a blockers. J Korean Med Sci. 2015;30(2):173-9.

27. Keane J, Gershon S, Wise RP, Mirabile-Levens E, Kasznica J, Schwieterman WD, et al. Tuberculosis associated with infliximab, a tumor necrosis factor a-neutralizing agent. N Engl J Med. 2001;345(15):1098-104. 
28. Bélard E, Semb S, Ruhwald M, Werlinrud AM, Soborg B, Jensen FK, et al. Prednisolone treatment affects the performance of the QuantiFERON gold in-tube test and the tuberculin skin test in patients with autoimmune disorders screened for latent tuberculosis infection. Inflamm Bowel Dis. 2011;17(11):2340-9.

29. Kleinert S, Kurzai O, Elias J, Marten K, Engelke C, Feuchtenberger M, et al. Comparison of two interferon- $\gamma$ release assays and tuberculin skin test for detecting latent tuberculosis in patients with immune-mediated inflammatory diseases. Ann Rheum Dis. 2010;69(4):782-4.

30. Gardam MA, Keystone EC, Menzies R, Manners S, Skamene E, Long R, et al. Anti-tumour necrosis factor agents and tuberculosis risk: mechanisms of action and clinical management. Lancet Infect Dis. 2003;3(3):148-55.

31. Giacomini E, lona E, Ferroni L, Miettinen M, Fattorini L, Orefici G, et al. Infection of human macrophages and dendritic cells with mycobacterium tuberculosis induces a differential cytokine gene expression that modulates T cell response. J Immunol. 2001;166(12):7033-41.

32. Pfeffer K, Matsuyama T, Kündig TM, Wakeham A, Kishihara K, Shahinian A, et al. Mice deficient for the $55 \mathrm{kd}$ tumor necrosis factor receptor are resistant to endotoxic shock, yet succumb to L. monocytogenes infection. Cell. 1993;73(3):457-67.

\section{Publisher's Note}

Springer Nature remains neutral with regard to jurisdictional claims in published maps and institutional affiliations.

Ready to submit your research? Choose BMC and benefit from:

- fast, convenient online submission

- thorough peer review by experienced researchers in your field

- rapid publication on acceptance

- support for research data, including large and complex data types

- gold Open Access which fosters wider collaboration and increased citations

- maximum visibility for your research: over $100 \mathrm{M}$ website views per year

At $\mathrm{BMC}$, research is always in progress.

Learn more biomedcentral.com/submissions 